\title{
Designing Improvement of Procurement Business Process Reengineering Approach : A Study Case of Insurance Company
}

\author{
Almira Rhea Masayu and M. Dachyar* \\ Industrial Engieneering Department, Universitas Indonesia
}

\begin{abstract}
Streamlining procurement process is one of the strategies to reduce cost of a company, especially in the insurance industry. This research aims to propose design improvement of procurement process in insurance company by implementing Business Process Reengineering (BPR) method. Data collection regarding procurement process was collected in one of life insurance company in Indonesia. This research uses BPR method which consist of three steps namely mapping as-is process, analyze as-is process, and modeling to-be process. Mapping as-is process using iGrafx standard Business Process Modeling and Notation (BPMN). Analyze as-is process by its process time to indicate problems. Modeling process to-be by using BPR best practices that will be prioritized using AHP method and selected using pareto analysis. Scenarios for to-be process then created based on the selected best practices, that will be inputed into the simulation model iGrafx standard BPMN. This research produces three scenarios of to-be process for procurement in Indonesian insurance company that reduce $35-76 \%$ of the process time compared to as-is process.
\end{abstract}

\section{Introduction}

Insurance company is one of the most threatened industry in service industry [1]. Reducing cost has been the most popular strategy that CEO chose to improve their company's growth [1]. Reducing company cost can be supported by process efficiency [2]. Cost classification of insurance company shows that operational cost is the highest cost of insurance industry [1]. Procurement, which is a term of a process of purchasing goods or services, contribute to $75 \%$ of the total operational cost of insurance company [3].

Surprisingly, procurement in insurance industry has the lowest improvement process compared to other industries (such as FMCG, professional service, government, health, manufacture, and telecommunication). The main cause of the lack of improvement in procurement is from the quality of the data [4]. Procurement in insurance industry takes a long time of end-to-end process, because of the manual process of organizing administration in procurement process [5].

A company can improve its process efficiency by re-organizing and re-designing process [6]. Changing process flow needed a transformation of its business process [7]. This research

* Corresponding author: mdachyar@yahoo.com 
aims to design improvement of the procurement process in one of the insurance company in Indonesia to increase its process efficiency with Business Process Reengineering (BPR) approach.

\section{Literature Review}

Business Process Reengineering (BPR) was first introduced by Davenport and Short and Hammer. BPR is a set of activities undertaken to achieve the results of the desired business process [8]. BPR were based on operational management theory, which is the design, activity, and improvement of systems that produce products or services. Operations Management focuses on the management of the entire system that produces finished goods as well as the process of delivering products to consumers [8]. BPR comes from the word "re-engineering". Reengineering is a fundamental way of thinking and a radical redesign of a business process to achieve dramatic improvement measured by its own measurement of cost, quality, service, and time [9]. Process innovation is one of the current innovation that organization concertrated on [8].

Data Flow Diagram (DFD) are visual tools for describing input and output models [10]. DFD consist of four notation, which are process, entity, storage, and flow [11]. The highest level of the DFD is a context diagram that provides an overview of a process. The next level is DFD level-0 which is the main process description. The level after level-0 is DFD level-1 which is the details of the process of each main process based on DFD level 0 [12].

Business Process Modeling Notation (BPMN) is a standard in capturing business processes in the early stages of system development [13]. BPMN represents graphic notations of business processes that facilitate understanding for business analysts and communication in business needs [14]. BPMN has four categories for graphical elements in building a model, namely Flow Objects, Connecting Objects, Swimlanes and Artifacts [15]. The application of BPMN is dominated by the main objectives such as documentation, redesign, continuous improvement, and knowledge management [16]

Analytical Hierarchy Process (AHP) is the most popular MCDM method used for research [17]. AHP is the first method introduced by Saaty, which is a method for problems with complex multi-criteria and takes into account both quantitative and qualitative aspects (Saaty, 1980).

\section{Methodology}

This research used BPR methodology approach. There are three main steps when conducting BPR method, which are modeling the as-is process, analyzing the as-is process, and modeling the to-be process. Preperation for step one -modeling as-is process- was done by creating procurement business process map using APQC framework to categorized process, SIPOC to see related stakeholders, and DFD to see flow of information on each process. Modeling the as-is process was created regarding the mapping of business process by APQC framework, SIPOC model, and DFD, by using simulation software iGrafx standard BPMN. As-is process analysis was observed by looking at the processing time in each of the activities in the as-is process model and benchmarking with the enablers to identify the problem. Modeling the to-be process are based on the best practices of BPR. Best practices were collected by literature review and then interviewing seven procurement expert in different insurance company in Indonesia to select best practice that are fit to the condition of insurance industry. Best practices then were prioritized by AHP method and selected by pareto analysis. The selected best practices will be incorporated into scenarios for the to-be process and simulated using iGrafx standard BPMN to see changes in processing time compared to the as-is process. Three scenarios were compared to see the lowest process time. 


\section{Results and Discussion}

\subsection{Procurement process map}

Before making the as-is process, the process map of the procurement process is designed using the APQC framework, by dividing the process into several levels. The APQC framework is used to categorize processes into five process levels, which are categories, group process, process, activities, and assignment (APQC, 2015). Four category of processes are: Planning and Analysis, Procurement Strategy, Contract and negotiation, Approvals and document handover, SIPOC (Supplier, Input, Process, Output, Customer) method is used to see who is acting as a stakeholder in the procurement process. Four Stakeholders have a role in the procurement process in the insurer ie, third-party companies (suppliers), finance departments, legal departments, and departments requesting goods or services.

\subsection{Modeling as-is process}

DFD was first created to see the flow of the documents for each process group. There are three main entities for the procurement process with each entitiy has its own documents that flows in and out of the entities. Level-0 DFD of procurement process sees a few problem regarding the storage based of the entire tender documents.. BPMN have the activity point of view of the entire business process, which means that from BPMN we can see the flow of each process, but cannot see the flow of the documents. Many manual process from the procurement end-to-end process. BPMN also found many approval process that can takes time to finish and effecting the continuous of the next process, which caused a bottleneck problem.

\subsection{Analysis of as-is process}

The as-is process takes about 202 days to process. The parameters the company has for the whole process is 55 days. There are nine type of process that have a high process time compared to the others, which is RFP revision, completing CST, vendor profile checklist, and Due Diligence Requirement (DDR), Completing Risk Assessment Checklist (RAC), RAC approval circulation, tender proposal submission, proposal clarification, price negotiation, PA/AF approval circulation, and contract negotiation.

The activity that have high process time will then be improved by using the BPR process improvement targets as an alternative to the to-be process. Table 1 shows the problem description regarding the observer and enabler on each activity.

Table 1. Problem identification regarding process as-is by BPMN iGrafx

\begin{tabular}{|l|l|l|}
\hline \multicolumn{1}{|c|}{ Process } & Problem identification & \multicolumn{1}{c|}{ Problem description } \\
\hline RFP revision & Bottleneck & $\begin{array}{l}\text { The revision takes a long time, the bidding } \\
\text { process cannot start if the RFP has not been } \\
\text { finalized. 70\% RFP through revision before } \\
\text { final RFP }\end{array}$ \\
\hline $\begin{array}{l}\text { Completing CST, Vendor } \\
\text { profile checklist, and Due } \\
\text { Diligence Requirement } \\
\text { (DDR) }\end{array}$ & $\begin{array}{l}\text { lack of an automated } \\
\text { system }\end{array}$ & $\begin{array}{l}\text { Filling and retrieving document templates } \\
\text { are done manually and in different places so } \\
\text { it takes time to retrieve documents }\end{array}$ \\
\hline $\begin{array}{l}\text { Completing Risk } \\
\text { Assessment Checklist } \\
\text { (RAC) }\end{array}$ & $\begin{array}{l}\text { lack of an automated } \\
\text { system }\end{array}$ & $\begin{array}{l}\text { Filling and retrieving document templates } \\
\text { are done manually and in different places so } \\
\text { it takes time to retrieve documents }\end{array}$ \\
\hline
\end{tabular}




\begin{tabular}{|l|l|l|}
\hline \multicolumn{1}{|c|}{ Process } & Problem identification & \multicolumn{1}{c|}{ Problem description } \\
\hline RAC approval circulation & $\begin{array}{l}\text { lack of an automated } \\
\text { system }\end{array}$ & $\begin{array}{l}\text { RAC hardcopy should be sent to several } \\
\text { departments to get signatures from each } \\
\text { department concerned }\end{array}$ \\
\hline $\begin{array}{l}\text { Tender proposal } \\
\text { submission }\end{array}$ & $\begin{array}{l}\text { lack of an automated } \\
\text { system }\end{array}$ & $\begin{array}{l}\text { The collection of proposals takes a long } \\
\text { time, so it can not go to the next stage }\end{array}$ \\
\hline Proposal clarification & $\begin{array}{l}\text { lack of an automated } \\
\text { system }\end{array}$ & $\begin{array}{l}\text { Customized schedule adjustments for each } \\
\text { related party }\end{array}$ \\
\hline Price negotiation & $\begin{array}{l}\text { lack of an automated } \\
\text { system }\end{array}$ & $\begin{array}{l}\text { Negotiations are done via email, missing } \\
\text { information due to email piling up, lack of } \\
\text { supplier response speed through email }\end{array}$ \\
\hline $\begin{array}{l}\text { PA/AF } \\
\text { circulation }\end{array}$ & $\begin{array}{l}\text { lack of an automated } \\
\text { system }\end{array}$ & $\begin{array}{l}\text { AF / PA hardcopy must be sent to several } \\
\text { departments to get the signature from each } \\
\text { department concerned }\end{array}$ \\
\hline Contract negotiation & $\begin{array}{l}\text { lack of an automated } \\
\text { system }\end{array}$ & $\begin{array}{l}\text { Negotiations are done via email, changes } \\
\text { should be discussed with some managers } \\
\text { from several departments concerned }\end{array}$ \\
\hline
\end{tabular}

\subsection{Modeling To-Be Process}

A literature study of BPR process improvement targets and adjustment of improvement targets on insurance conditions in Indonesia by appraising experts from several insurance companies in Indonesia. Literature study found 29 best practices of BPR. Seven (7) procurement insurrance expert in different insurance companies in Indonesia selected to 16 best practices by using Delphi Method.

AHP method is selected to find weighted importance from 16 BPR best practice and perform pareto diagram to prioritize business improvement. The weighted of importance of BPR best practices are Task Automation (13.1\%), Resequencing (10.3\%), Parallelism (10\%), Technology Integration (9.6\%), Triage (9.4\%), Empowerement (6.8\%), Task Elimination (6.4\%), Specialist Generalist (5.2\%), Task Composition (5\%), Order Type (4.4\%), Knockdown (4.3\%), Contact Reduction (3.7\%), Interfacing (3.7\%), Exception (3\%), Case Manager (2.8\%), Extra Resource (2.3\%).

Three scenarios which are scenario 1 (without automation) takes 147 days on Figure.1. Scneario 2 (half automation) takes 58,17 days, and scenario 3 (full automation) takes 50 days. Scenario three has the greatest impact on reducing processing time, which can decrease to 50 days. 


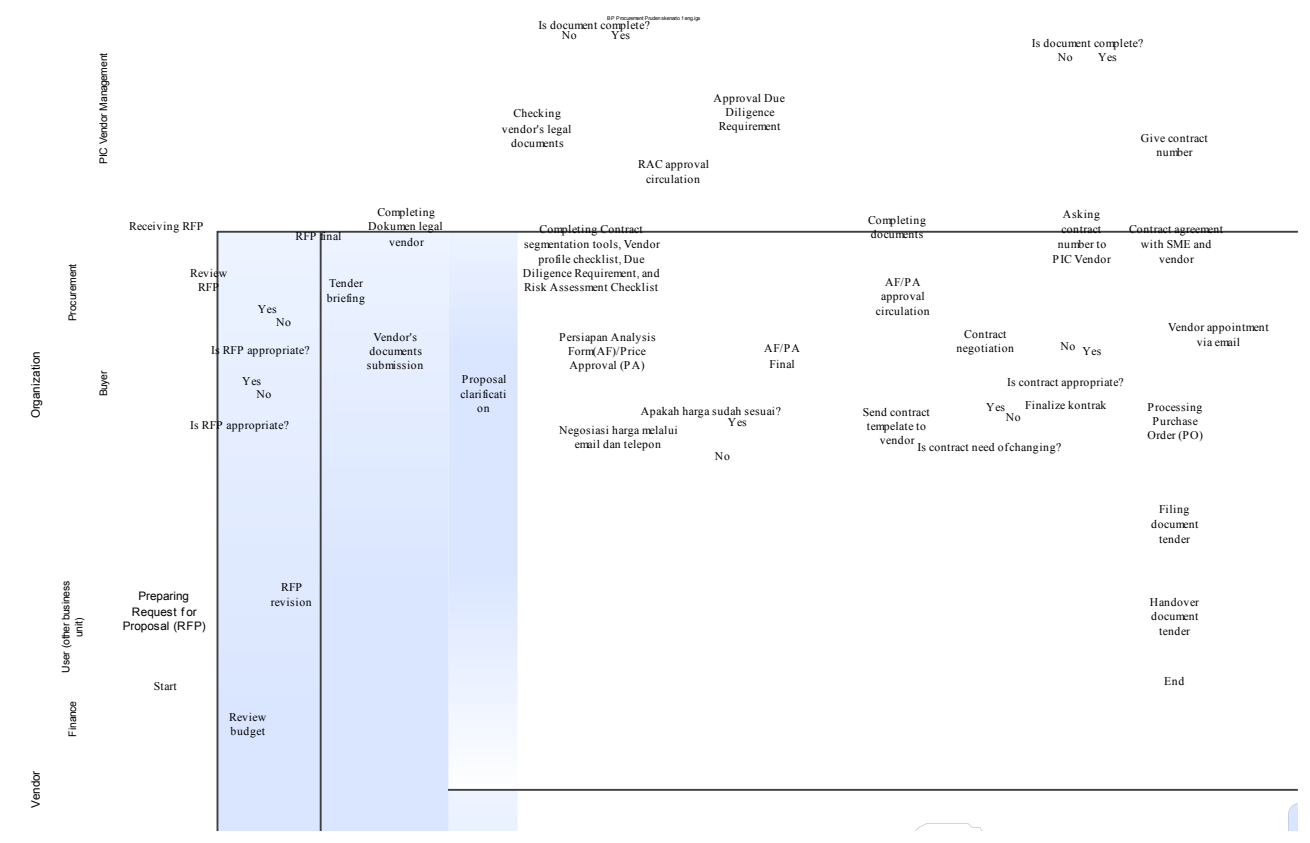

Fig. 1. Scenario 1 BPMN proses to-be

\section{Conclusion}

This research found the effective use of 16 best practices in procurement process of one of Indonesian insurance company, which are task automation, technology integration, parallelism, resequencing, order type, generalist-specialist, task composition, task elimination, empowerment, and triage.

Based on three scenarios, the best conditions are in the third scenario that is to automate the entire process. The third scenario resulted in a reduction in processing time of $76.48 \%$. The third scenario shows that technology integration strategies can reduce processing time so as to achieve company standards.

\section{References}

1. PWC, (2017).

2. I. Cotter, (2015).

3. G. Sibanda, (2016).

4. Deloitte, The Creative Studio (2017).

5. V. Adhityahadi, (2017).

6. T. Munyard, J. Schade, (2017).

7. S. Kaniyar, P. Peters. (2015).

8. A. D. Cruz, E. E. V. Martinez, J. M. M. Hincapie i F. R. Torres, Intgbl Cap, (2016).

9. T. E. Erkan, Engr. and Tech. Int. J. of Econ. and Mgmt. Engr 3, (2009).

10. P. Larsen, N. Plat i H. Toetenel, Form. Asp. Compu, (1994). 
11. F. Schmalenberg i R. Vandenhouten, International Symposium on Applied Machine Intelligence and Informatics, (2016).

12. P. M. Jacob, I. M. H, J. Jose i J. Jose, International Conference on Information Science, (2016).

13. R. M. Dijkman, M. Dumas i C. Ouyang, Info. and S. W, Tech., (2008).

14. R. K. Ko, S. S. Lee i E. W. Lee, Bus. Prcss. Mgmt. J., (2009).

15. M. Chinosi i A. Trombetta, Computer Standards \& Interfaces, (2012).

16. J. Recker, Bus. Prcss. Mgmt. J., (2010).

17. S. D. Pohekar i M. Ramachandran, Renewable and Sustainable Energy Reviews, (2004). 